Revista lus et Praxis, Año 24, No 2, 2018, pp. 595 - 620

ISSN 0717 - 2877

Universidad de Talca - Facultad de Ciencias Jurídicas y Sociales

Compensaciones económicas por trabajo doméstico y de cuidados

Mercedes Robba - Romina Lerussi

Trabajo recibido el 7 de septiembre de 2016 y aprobado el 2 de noviembre de 2017

\title{
Compensaciones económicas por trabajo doméstico y de cuidados tras la disolución del matrimonio por divorcio, o de la pareja por cese de la unión convivencial en Argentina. Una lectura jurídica feminista
}

ECONOMIC COMPENSATION FOR DOMESTIC WORK AND CARE AFTER THE DISSOLUTION OF THE MARRIAGE BECAUSE OF DIVORCE, OR THE COUPLE FOR CESSATION OF CONVIVIAL UNION IN ARGENTINA. A FEMINIST LEGAL READING

MerCeDes RobBA*

ROMINA LERUSSI ${ }^{* *}$

\section{RESUMEN}

Presentamos la figura de la compensación económica posdivorcio o cese de unión convivencial, en especial por trabajo doméstico y de cuidados. Exponemos un análisis dogmático de la misma siguiendo el nuevo Código Civil y Comercial de la Nación Argentina (2014) e introducimos algunos comentarios sobre violencia patrimonial y patrimonio invisible.

ABSTRACT

We present the figure of the economic compensation post divorce or cessation of convivial union, particularly because of domestic work and care. We introduce a dogmatic analysis of that figure in the Civil and Commercial Code of Argentina (2014) and we expose some comments about patrimonial violence and invisible heritage.

\footnotetext{
* Abogada, especialista en Derecho de Familia (Universidad de Buenos Aires). Docente de Derecho de Familia y Sucesiones (Universidad de Buenos Aires, Argentina) y de Derecho Civil V (Universidad del Salvador, Argentina). Alumna de la Carrera de Especialización en la Magistratura de la Escuela de Servicio de Justicia (Procuración General de la Nación, Defensoría General de la Nación y Universidad Nacional de la Matanza, Argentina). Actualmente trabaja en la Unidad de Letrados de personas menores de edad (art. 22, Ley No 26.657 de la Defensoría General de la Nación, Argentina). Ha publicado diversos artículos sobre temáticas como el matrimonio, el divorcio, la adopción, la violencia de género, entre otros. Ciudad Autónoma de Buenos Aires, Argentina. Correo electrónico: mercedesrobba@gmail.com.

** Doctora en Ciencias Sociales por la Universidad de Buenos Aires. Investigadora asistente en el Consejo Nacional de Investigaciones Científicas y Técnicas (Conicet) con lugar de trabajo en el Área de Feminismos, Género y Sexualidades (FemGeS), Facultad de Filosofía y Humanidades, Universidad Nacional de Córdoba. Miembro del Proyecto Zonas grises de la esclavitud femenina, Facultad de Derecho, Universidad de Granada (España) y del Proyecto Derecho y Control, Centro de Investigaciones Jurídicas y Sociales, Universidad Nacional de Córdoba (Argentina). Área de investigación: Pensamiento Jurídico Feminista. Ciudad de Córdoba, Argentina. Correo electrónico: rclerussi77@gmail.com.
} 


\section{PaLABRAs Clave \\ Divorcio o cese de unión convivencial; compensaciones económicas; trabajo doméstico y de cuidados \\ KEY WORDS \\ Divorce or cessation of convivial union; economic compensation; domestic work and care}

\section{Introducción}

El nuevo Código Civil y Comercial de la Nación Argentina $(\mathrm{CCyCN})^{1}$ ha incorporado grandes modificaciones en materia de divorcio y cese de uniones convivenciales, entre las que se destaca la aplicación de la figura de la compensación económica tras la disolución del matrimonio o de la pareja convivencial. Esta innovación legal trae nuevos desafíos tanto para la labor judicial en todos sus niveles como para la sociedad en general, en tanto plantea una serie de cuestiones no atendidas (o al menos no con tal contundencia) como las relativas a la validación y consideración del trabajo doméstico y de cuidados en dichas situaciones.

La no consideración de estos aspectos tuvo durante largo tiempo no sólo implicancias en lo atinente al derecho de familia, sino que es menester comprender que esta concepción del trabajo doméstico y de cuidados y de su naturaleza jurídica no es puntual o esporádica, viene de las concepciones que se tienen de este trabajo en todo el sistema jurídico (por ejemplo en lo referido a los derechos laborales de las personas que se insertan en el sector doméstico o de casas particulares en la Argentina). Sumado al hecho fáctico de que se trata de un tipo de trabajos (tanto remunerado como no remunerado) realizado en su mayoría por mujeres en sentido amplio. De lo que se sigue la responsabilidad de los actores legales en comprender estas implicancias, dada la magnitud de sus decisiones, en el modo en que perpetúan el estatus vulnerable de aquellas mujeres que trabajan con y sin obtener un salario por realizar trabajo doméstico y de cuidados ${ }^{2}$.

Uno de los efectos que produce el divorcio está constituido por la posibilidad de solicitar una compensación económica. Así, el artículo 441 del CCyCN (2014) establece: "[e]l cónyuge a quien el divorcio produce un desequilibrio manifiesto que signifique un empeoramiento de su situación y que tiene por causa adecuada el vínculo matrimonial y su ruptura, tiene derecho a una compensación. Esta puede consistir en una prestación única, en una renta por tiempo determinado $o$, excepcionalmente, por plazo indeterminado". Del mismo articulado puede

${ }^{1}$ Ley No 26.994, de 2014.

2 Silbaugh (1996). 
extraerse la definición de este instituto, su procedencia como así también la legitimación activa y la pasiva.

A su vez, el nuevo CCyCN incluye por primera vez en su regulación a las uniones convivenciales. Según el artículo 509, se entiende por unión convivencial: "la unión basada en relaciones afectivas de carácter singular, pública, notoria, estable y permanente de dos personas que conviven y comparten un proyecto de vida común, sean del mismo o de diferente sexo". El cese de la unión convivencial produce ciertos efectos, entre ellos se regula la compensación económica. Al respecto, el artículo 524 -en iguales términos que el artículo 441- establece el derecho a pedir una compensación económica en los casos en que, cesada la convivencia, uno de los convivientes sufra un desequilibrio manifiesto que signifique un empeoramiento de su situación económica.

La figura de la compensación económica presenta una serie de dificultades interpretativas que son menester dilucidar a partir de argumentos que puedan efectivizarla y dinamizarla en la vida práctica. Según algunos/as autores/as, dichas dificultades provienen de la confusión que introduce el divorcio vincular o el cese de la unión convivencial que, por un lado, desean extinguir los vínculos de solidaridad de la pareja pero, por otro lado, se intenta no perjudicar en demasía a ninguna de las dos partes. Para eso, la nueva regulación civil se encarga de establecer ciertas pautas que los/las operadores jurídicos deben tener en cuenta para su otorgamiento y a la hora de su fijación, entre las que mencionan: la dedicación que cada cónyuge/conviviente brindó a la familia y a la crianza y educación de hijos/as y la capacitación laboral y la posibilidad de acceder a un empleo del cónyuge/conviviente que solicita la compensación económica, entre otras (artículos 442 y 525) ${ }^{3}$.

Jurídicamente la compensación económica no es ni un supuesto de responsabilidad civil ni una obligación alimenticia y podría configurarse como un tipo de indemnización por afectación legal de derechos ${ }^{4}$. También es considerada una

\footnotetext{
${ }^{3}$ A lo largo del presente texto y de acuerdo al caso, indicaremos en las marcas gramaticales tanto el masculino como el femenino. Parte de la invisibilización y exclusión de lo femenino, y por lo tanto de las mujeres en el lenguaje jurídico, pasa por el no reconocimiento de este aspecto.

${ }^{4}$ CoRral TAlCiAnI (2007). El autor referido también habla de indemnización por afectación autorizada de derechos. Al respecto cabe decir que la noción de afectación legal de derechos es problemática, al menos desde el punto de vista de un análisis más profundo y situado de las implicancias que tiene la autonomía de una voluntad que decide que legalmente sean afectados sus derechos (en el contexto de desigualdad estructural en todos los ámbitos de la vida, particularmente de las mujeres). Con todo, este término parece más preciso en comparación con otras posturas que entienden a las compensaciones en términos de indemnización por sacrificio o incluso deberes de socorro. En otro orden y en el marco de la legislación chilena, CORRAL TALCIANI (2007) sostiene además que este tipo de indemnización puede ser "aprovechada" en tanto se hayan respetado los deberes conyugales. En este sentido, habría que
} 
institución que: "se erige como una herramienta legal que posibilita y favorece una cierta igualdad real en las condiciones y oportunidades en que cada cónyuge se encuentra una vez finalizado su proyecto de vida en común, condiciones que se vieron afectadas y desbalanceadas justamente a causa de dicho quiebre. En definitiva, la finalidad de la compensación económica configura su naturaleza jurídica sui generis" ${ }^{\prime \prime}$. El requisito esencial exigido sería entonces que una de las partes del matrimonio o de la pareja conviviente, sea por causa de divorcio o cese de la convivencia, sufra un menoscabo económico. Este menoscabo podrá devenir en la mayoría de los casos de la dedicación de una de las partes al hogar, trabajo de cuidados y domésticos, que habrá que definir y analizar.

En este marco, aparecen una serie de supuestos jurídicos tales como la misma definición de trabajo doméstico y de cuidados y su valoración a la hora de la delimitación, y sus implicancias en las compensaciones en tratamiento. Aspectos, entre otros, que deberán ser revisados a la luz no sólo de la nueva normativa, sino de los alcances que tiene sobre su interpretación el progresivo proceso de constitucionalización del derecho privado.

En el presente trabajo y desde vertientes jurídicas feministas, presentamos, en primer lugar, algunos problemas teóricos en torno a la figura de la compensación económica posdivorcio o cese de unión convivencial, en especial por trabajo doméstico y de cuidados. En segundo lugar, exponemos un análisis dogmático de esta figura en el nuevo $\mathrm{CCyCN}$ de Argentina e introducimos algunos comentarios críticos sobre dos aspectos puntuales: la violencia patrimonial que podría ejercerse en caso de no otorgarse las compensaciones y el patrimonio invisible que debería considerarse para su cuantificación.

evaluar qué se entiende por deberes conyugales de acuerdo a cada legislación y si es convergente atender a esta cuestión en la evaluación de las compensaciones. Por ejemplo, en lo referido al deber de fidelidad, muy común en las legislaciones de tradición continental y cuyas críticas no desarrollamos, entendemos que el incumplimiento del deber conyugal no debería ser valorado a la hora de analizar la procedencia del derecho a compensación económica por trabajo doméstico y de cuidados realizado en forma gratuita normalmente por una mujer. Cabe aclarar que en Argentina no se tienen en cuenta los deberes conyugales a los efectos de la compensación. De hecho, el único deber jurídico que regula el CCyCN (2014) es el de asistencia, puesto que se han eliminado el deber jurídico de fidelidad y de cohabitación. El incumplimiento del deber de asistencia posibilita el reclamo de alimentos durante el matrimonio ya que es, en principio, durante ese tiempo donde rige el deber conyugal. Si bien el CCyCN regula alimentos posdivorcio, lo hace de manera limitada a dos supuestos: la enfermedad grave preexistente al divorcio que impide el autosustento y la falta de recursos propios suficientes o la imposibilidad razonable de procurárselos. En el último supuesto, los alimentos no proceden a favor de quien recibe la compensación económica (artículos 434, inc. a y b, respectivamente). En estos casos, el criterio para su procedencia es la situación de vulnerabilidad de una de las partes y el principio de solidaridad; mientras que, en los supuestos de compensación económica, el criterio es siempre el desequilibrio económico.

5 Pellegrini (2014), p. 459. 


\section{Las compensaciones económicas por trabajo doméstico y de cuidados}

\subsection{Planteos teóricos}

La figura de la compensación económica por trabajo doméstico y de cuidados posdivorcio o disolución de unión convivencial es el resultado de un largo proceso de reconocimiento y visibilización no sólo del valor económico que implica este trabajo para las economías familiares y estatales, sino de su necesidad para la vida humana. Según algunas economistas feministas, si se prescindiera de este trabajo por un día, colapsarían además de las unidades domésticas, las economías del mercado capitalista actuales ${ }^{6}$. Aún más, se trata de un trabajo sin el cual no habría sociedad ${ }^{7}$. Por lo tanto, para entender la figura en tratamiento, es fundamental hacerlo no sólo desde el punto de vista de las relaciones familiares y de sus normas (derecho de familia y relativos) sino además del modo en que esta figura se articula con las políticas sociales y normativas económicas, financieras, laborales y todas las que dan forma al Estado de bienestar ${ }^{8}$.

Ahora bien, ¿por qué la consideración de este trabajo imprescindible realizado de manera remunerada y no remunerada no ha sido tenido en cuenta o valorado lo suficiente en las economías y en el derecho contemporáneos? Las razones han sido centralmente ontopolíticas y conceptuales. Los supuestos hegemónicos que fundamentan las economías de mercado actuales de raíz neoclásica (donde economía se asocia al mercado, la industria/empresa, el dinero, el salario, el valor de cambio, términos productivos), y que impregnan a su vez al derecho liberal, han entendido al término trabajo como empleo, es decir, trabajo mercantil remunerado o asalariado.

En ese sentido, en el derecho las regulaciones en materia de trabajo desde el siglo XIX han estado conformadas por argumentos de tipo económico dentro de lo que se conoce como la lógica utilitaria9 . El punto de referencia paradigmático del derecho del trabajo fue la empresa como fuente productora de bienes para el mercado ${ }^{10}$. Ello tuvo como efecto, entre otros, regulaciones

\footnotetext{
6 Carrasco (2001).

7 Fineman (2004). A lo largo del presente texto usamos el término trabajo doméstico y de cuidados en conjunto, entendiendo el término doméstico como derivado del latín domus en la denominación referida o perteneciente a la casa. Esta acepción es la asumida por la Organización Internacional del Trabajo (OIT) en el Convenio 189 del año 2011, cuando refiere al trabajo doméstico como aquel realizado en un hogar $u$ hogares o para los mismos.

8 Pitch (1998); Pautassi (2000).

9 Pérez Orozco (2005).

10 Machado (2003).
} 
laborales del trabajo doméstico remunerado o empleo doméstico de carácter marginal, alegando que aun tratándose de una forma de contrato de trabajo, su desenvolvimiento no afectaba a la vida industrial, ni a las empresas mercantiles ni su ejercicio suponía una actividad económicamente productora. Lo cual hizo que este empleo valiera menos, incluso en los nuevos marcos dados por la Organización Internacional del Trabajo (OIT) y por las reformas legislativas estatales en la materia como en el caso argentino ${ }^{11}$. Y, además, como efecto de lo que se entiende no solo por trabajo, sino en particular por trabajo doméstico y de cuidados no remunerados o gratuitos. Dicho en otros términos, "el trabajo doméstico remunerado es tratado de una manera que lo acerca mucho más al trabajo doméstico no remunerado que a cualquier otro tipo de trabajo pago; y su tratamiento refuerza el argumento de que la influencia que tiene cada doctrina legal que devalúa el trabajo doméstico es potenciada por su repetición a lo largo de todo el sistema legal"12.

Este ensamble semántico no ha sido ingenuo sino más bien parte de las operaciones de exclusión de todo aquello que por no remunerado, o siendo remunerado no valorado como tal, ha sido retirado de la esfera de lo que cuenta para la economía de mercado y el derecho. Operación, vale decir, íntimamente vinculada con la división heterosexual del trabajo cuyo entramado se configura a partir de una serie de dicotomías articuladas (trabajo/no trabajo; productivo/ reproductivo; autónomo/dependiente, economía/no economía, masculino/femenino, varón/mujer), es decir, de dualismos que chorrean mitología sexista ${ }^{13}$. Este orden retórico fue fundamental para la producción de una cierta manera de entender no sólo la economía y el derecho, generando nuevas figuras progresivamente normalizadas y por lo tanto naturalizadas (la del proveedor, la del ama de casa, entre otras), sino de concebir todo el orden social ${ }^{14}$. En este sentido, en la división heterosexual: "[...] se asigna a los hombres [léase: varones] la responsabilidad primaria como proveedores del sustento y a las mujeres la responsabilidad primaria como cuidadoras y nutridoras, y luego, [se] trata los patrones de personalidad derivados de esta división como si fueran fundamentales [léase: fundamentos naturales u ontológicos]. Es como si los proveedores hombres [varones] absorbieran dentro de su personalidad la independencia asociada con su papel económico ideológicamente interpretado, mientras que

11 Nos referimos al Convenio OIT No 189, de 2011 Trabajo decente para trabajadores/as domésticos/ as y, en Argentina, a la Ley № 26.844, de 2013 que crea el Régimen Especial de Contrato de Trabajo para el Personal de Casas Particulares.

12 Silbaugh (1996), p. 127.

13 Mccloskey (1993).

14 LeRUSSI (2014). 
la personalidad de las mujeres suministradoras de cuidado y alimento se saturara con la dependencia de aquellos a quienes cuidan. De esta manera, la oposición entre la personalidad independiente y la dependiente se dibuja sobre el mapa de una serie de oposiciones jerárquicas y dicotómicas fundamentales para la cultura capitalista contemporánea"15.

En fin, ésta ha sido parte de la base sobre la cual se han sostenido los engranajes teóricos, técnicos y políticos que conforman la vida sociojurídica contemporánea de nuestras comunidades.

El trabajo doméstico y de cuidados comenzó a configurarse como objeto específico de análisis y estudios a finales de la década de los sesenta y especialmente en los setenta ${ }^{16}$. Este proceso se dio en el marco de las transformaciones en las vidas de las mujeres y de las sociedades en general en todos los planos. En este sentido, la labor del pensamiento feminista, en sus variadas vertientes jurídicas, económicas, sociales, ha sido fundamental para visibilizar y dar cuerpo teórico y práctico a estos asuntos ${ }^{17}$. Todo lo cual ha generado un sinnúmero de inputs en el derecho, provocando modificaciones en los sistemas jurídicos e investigaciones en la materia de acuerdo a las características de cada lugar. En algunos contextos encontramos casos ejemplares, aunque aún aislados, que integran el tratamiento legal de este tipo de trabajo no sólo en el derecho de familia sino además en el derecho contractual, de seguridad social, de responsabilidad civil, impositivo, de la asistencia social y laboral ${ }^{18}$.

A continuación nos detenemos en uno de los aspectos centrales de la figura en tratamiento referido a la definición y valoración del trabajo doméstico y de cuidados, abordaje útil y necesario para pensar los supuestos conceptuales y sus efectos prácticos en las interpretaciones jurídicas de este instituto.

\footnotetext{
15 Fraser (1997), pp. 199-200.

${ }^{16}$ Hay antecedentes previos como el movimiento de las ciencias domésticas en la década de 1920 en Estados Unidos y los desarrollos de raíz neoclásica en economía de Margaret ReAD (1934) de gran influencia por cierto. Vale decir que ReAD (1934) introdujo el criterio de la tercera persona en la definición del trabajo doméstico a partir de la categoría de función doméstica. En sus términos: "la producción doméstica incluye únicamente las actividades no remuneradas ejercidas por y para los miembros de la familia, actividades que pueden ser reemplazadas por productos mercantiles o servicios remunerados cuando circunstancias como los ingresos, la situación del mercado y las preferencias permiten delegar servicios en una persona ajena a la familia (citada en BorDeríAs et al., 1994, p. 38). De esta manera se complejizó la idea de la familia entendiéndola como unidad de producción y no sólo unidad de consumo y/o de oferta de trabajo (propia de la escuela marginalista de la que es heredera la neoclásica). Este criterio es el utilizado en algunos contextos para el cálculo de las compensaciones económicas que estamos tratando.

17 Para profundizar al respecto, sugerimos Carrasco (1991; 1999); Borderías, Carrasco y Alemany (1994); Pérez Orozco (2005).

18 Silbaugh (1996).
} 


\subsection{Problemas de definición y valoración monetaria del trabajo doméstico y de cuidados}

Frente a casos de divorcio o cese de la unión convivencial, la primera forma que habitualmente consideran las legislaciones en materia de compensaciones económicas por trabajo doméstico y de cuidados es la fijación de un monto por mutuo acuerdo de las partes. En la doctrina española encontramos que, de no darse esta situación, la vía más común es la del criterio de la tercera persona, es decir, se calcula a partir del salario que se hubiera tenido que pagar por la contratación de personal para la realización del trabajo doméstico y de cuidados a lo largo del período que haya durado el vínculo. Esto es lo que se conoce como el coste de reemplazo o de sustitución ${ }^{19}$. De esta forma, el cálculo se basa sobre el criterio de lo que se deja de desembolsar porque se contribuye de manera gratuita o, de lo que se ahorra frente a la no contratación de personal dada la dedicación exclusiva o semiexclusiva de una de las partes a este trabajo, en general, las mujeres.

Otro criterio es el del coste de oportunidad, el cual: "pretende registrar las oportunidades que se pierden, o se aplazan, por dedicarse al trabajo doméstico, en lugar de aplicar todo su potencial al mercado de trabajo ${ }^{\prime 20}$. Es la situación de las mujeres que se dedican a este trabajo de manera gratuita, abandonando su profesión u oficio para dedicarse de manera exclusiva o semiexclusiva a las tareas domésticas y de cuidado. Dada la situación de divorcio o disolución del vínculo convivencial, éste coste es una vía (aún incipiente) de valoración

\footnotetext{
${ }^{19}$ MURILLo (1996).

20 MuriLlo (1996), p.22.

Un ejemplo jurisprudencial en el contexto argentino donde se aplicó el criterio del costo de reemplazo como argumento para solicitar indemnización en el caso de una trabajadora del hogar remunerada, lo encontramos en un fallo de la Cámara Nacional de Apelaciones del Trabajo (CNAT./Argentina), sala VI, 26/12/1992, en autos "Lacuadra, Ernesto c/ Soc. Anónima Nestlé de Productos Alimenticios" (TSS, 1993, p. 366, citado en ACKERMAN (2000), p. 41). En este fallo se sostuvo: "el reclamo sobre el que se pronuncia el Tribunal es del marido de una trabajadora doméstica fallecida en un accidente de trabajo. Éste, en su nombre y en el de sus hijos, pretende una reparación integral de los daños y perjuicios sufridos, con fundamento en las normas del [anterior] Código Civil. Si bien se acoge la pretensión, no se hace lugar al pago de una indemnización por los gastos originados en la contratación de una empleada doméstica para la realización de tareas hogareñas, que hasta su fallecimiento, realizaba la trabajadora. El argumento del sentenciante para este rechazo es que 'dichos gastos no reflejan un empobrecimiento patrimonial, en cuanto constituyen el precio de un servicio que los interesados recibían antes a título gratuito, ya que no se puede afirmar que tenían un derecho subjetivo a las prestaciones gratuitas de la esposa y madre, de donde el hecho de que su falta haya convertido esas prestaciones en onerosas no implica que esos gastos deban ser compensados por el responsable'" (ACKERMAN (2000), p. 42). Según el mencionado autor, en este caso se produce discriminación, no por aplicación o interrupción de una norma legal, sino de la propia sentencia cuyo presupuesto central es que el trabajo de la mujer en el hogar es gratuito y no supone ventaja comparativa económica para la familia.
} 
compensatoria. De cualquier modo, los criterios esbozados no dejan de tener algunos problemas a la hora de valorar monetariamente lo que se conoce como el patrimonio invisible de la familia o comunidad doméstica, que en muchos casos no se traduce literalmente en estos términos y que suele capitalizar uno de los integrantes (en parejas heterosexuales, comúnmente el varón) ${ }^{21}$.

En este panorama, vemos que los problemas del cálculo de las compensaciones económicas por trabajo doméstico y de cuidados pueden ser múltiples. Tal como indicáramos, uno de los riesgos principales radica en aplicar directamente a la organización del trabajo doméstico, parámetros industriales o de mercado, es decir criterios de racionalidad económica -eficiencia, productividad, rentabilidad- propios de las perspectivas economicistas de corte neoclásico. El problema que se plantea es que si no se le asigna valor de mercado a las actividades del hogar, se corre el riesgo de que dichas actividades permanezcan olvidadas y junto con ellas se mantenga en la invisibilidad a las personas que las realizan: las mujeres. Como efecto, se crean condiciones de empobrecimiento progresivo para ellas frente a disoluciones vinculares y en un contexto de gran desigualdad estructural ${ }^{22}$.

Los feminismos en economía han aportado significativos elementos conceptuales y prácticos para medir y valorar el trabajo doméstico y de cuidados, útiles para el cálculo y la definición de las compensaciones económicas que estamos tratando. Se ha desarrollado un sinnúmero de tecnologías sobre medición y cuantificación con objetivos variados, desde el diseño de cuentas satélites, las encuestas sobre el uso del tiempo, entre otras. En este marco encontramos dos grandes modalidades de estimación o valoración: "las que se basan en el coste de los inputs de trabajo (cantidad y calidad del tiempo utilizado en la obtención de bienes y servicios) ampliamente desarrolladas y utilizadas por una serie de economistas; y las que utilizan el valor del output familiar (producto obtenido como resultado de un proceso productivo), método más reciente y menos extendido" 23 .

Con todo, los métodos de valoración más extendidos son referidos a los inputs que toman como referente alguna tasa salarial. Es decir, el criterio de la tercera persona, el cual considera trabajo doméstico y de cuidados a aquella actividad

21 РітCH (1998).

22 Carrasco (1999).

23 Borderías et al. (1994), p. 39. Para conocer algunos métodos de estimación y valoración del trabajo doméstico y de cuidados, sea bajo el criterio de los inputs como de los outputs, véase: BORDERías et al. (1994); Alabart et al. (2004); Pérez Orozco (2005). En relación con estudios sobre uso del tiempo, Durán (1997); entre las argentinas, véase: Esquivel (2009). En materia de enfoques macroeconómicos en la materia, ver Carrasco (1999); Picchio De Mercato (2001); De Villota (2003). 
realizada en el ámbito de la unidad doméstica que podría ser realizada por una persona distinta de la que se beneficiaría de su servicio, es decir, que pueda ser intercambiada en términos mercantiles. Este es un criterio ampliamente aceptado, aunque a nuestro juicio arrastra problemas propios de los razonamientos neoclásicos en economía (individuos racionales que intentan maximizar la satisfacción de sus necesidades evaluando costes). Así, se extienden dichos supuestos a todos los aspectos de la vida, explicando también el matrimonio, la unión convivencial, el divorcio o anulación de la unión, en términos de beneficios, ganancias y pérdidas que puede reportar la vida en pareja ${ }^{24}$.

En fin, consideramos que las compensaciones económicas pueden ser pensadas en esta clave patrimonial (que es la corriente principal esgrimida), es decir, el criterio de la tercera persona. Sin embargo es importante atender a dos cuestiones. La primera es que el sector laboral de referencia sobre el que comúnmente se hace el cálculo de las compensaciones, es decir el sector doméstico, es un sector precarizado y con salarios por debajo de otros sectores. La segunda es que el eje de la valoración debería atender a la consideración en sí del trabajo doméstico y de cuidados como trabajo que tiene valor (no solo monetario) para la sostenibilidad de la vida ${ }^{25}$.

En el siguiente apartado, y para situar los aspectos teóricos referidos, nos dedicamos a analizar dogmáticamente la figura de la compensación económica en caso de divorcio o cese de unión convivencial tal como se plantea en el nuevo CCyCN (2014) de Argentina, para pensar particularmente en el trabajo doméstico y de cuidados gratuitos o trabajo no remunerado en los términos utilizados por Highton (2015).

\section{La compensación económica posdivorcio o cese de unión convivencial en el nuevo Código Civil y Comercial de la Nación Argentina}

\subsection{Análisis dogmático}

La compensación económica es una figura que está prevista en el nuevo CCyCN argentino como uno de los efectos del divorcio y, también, del fin de la unión convivencial.

En primer lugar, en relación con el divorcio, el artículo 441 del CCyCN establece la posibilidad de que el/la cónyuge, a quien el divorcio le produce un desequilibrio manifiesto que signifique un empeoramiento de su situación y que tiene por causa adecuada el vínculo matrimonial y su ruptura, pueda solicitar una compensación. Ésta puede consistir en una prestación única, en una renta

${ }^{24}$ VANDELAC (1985), p. 172.

${ }^{25}$ Carrasco (2001). 
por tiempo determinado o, excepcionalmente, por plazo indeterminado. Puede pagarse con dinero, con el usufructo de determinados bienes o de cualquier otro modo que acuerden las partes o decida el o la juez/a.

Entonces, la norma dispone que para que la compensación económica proceda es necesario que el divorcio haya producido un desequilibrio manifiesto que signifique un empeoramiento de la situación de uno/a de los cónyuges y que tenga su causa en el vínculo matrimonial y su ruptura. En otras palabras, esta figura procede cuando, luego del divorcio, una de las partes ha quedado en peor situación económica en comparación con la que se encontraba mientras estaba casada/o y que, justamente, tiene su origen en el matrimonio y su disolución. Para ejemplificar, la compensación económica procederá, sin dudas, en aquellos casos en que, durante el matrimonio, la mujer tuvo asignado el rol de cuidadora de hijos/as y del hogar, y el varón fue quien tuvo asignado el rol proveedor económico con inserción en el mercado laboral.

El CCyCN dispone que, al momento del divorcio, los cónyuges pueden realizar un convenio que regule todos sus efectos (división de bienes, cuidado de hijos/as, alimentos, etcétera). Entre estos efectos pueden pactar la compensación económica. Si los cónyuges no se ponen de acuerdo, una de las partes puede solicitar la fijación judicial de la compensación económica ${ }^{26}$. En este caso, se deberá determinar la procedencia y el monto de la compensación económica sobre la base de diversas circunstancias, entre ellas: a) el estado patrimonial de cada una de las partes al inicio y a la finalización de la vida matrimonial; b) la dedicación que cada cónyuge brindó a la familia, a la crianza y la educación durante el matrimonio y la que debe prestar con posterioridad al divorcio; c) la edad y el estado de salud de cónyuges e hijos y/o hijas; d) la capacitación laboral y la posibilidad de acceder a un empleo del o de la cónyuge que solicita la compensación económica; e) la colaboración prestada a las actividades mercantiles, industriales o profesionales del otro cónyuge; f) la atribución de la vivienda familiar, y si recae sobre un bien ganancial, un bien propio, o un inmueble arrendado. En este último caso, quién abona el canon locativo (artículo 442 del CCyCN).

La acción para reclamar la compensación económica caduca a los seis meses contados desde que se dictó la sentencia de divorcio.

\footnotetext{
26 Si bien excede el objeto del presente artículo plantear cómo debe procederse en caso de incumplimiento del pago de la compensación económica, solo mencionaremos que en el supuesto de que la compensación económica sea fijada por acuerdo de las partes, deberá homologarse ese acuerdo y ejecutarse judicialmente. Mientras que si la compensación económica es fijada judicialmente, ante el incumplimiento del pago se procederá a su ejecución judicial (arts. 499 y ss., Código Procesal Civil y Comercial de la Nación y art. 719, CCyCN).
} 
Al respecto, en los Fundamentos del Anteproyecto de CCyCN (2014), la Comisión redactora sostuvo: "[e]l Anteproyecto recepta una figura que tiene aceptación en varias legislaciones del derecho comparado, y que es coherente con el régimen incausado de divorcio; en efecto, con fundamento en el principio de solidaridad familiar y en que el matrimonio no sea causa fuente de enriquecimiento o empobrecimiento económico de un cónyuge a costa del otro, se prevé la posibilidad de que, para aminorar un desequilibrio manifiesto, los cónyuges acuerden o el juez establezca compensaciones económicas. Estas compensaciones pueden ser abonadas de diferentes modos: prestación dineraria única; renta por un tiempo determinado o, de manera excepcional, por plazo indeterminado. Por ejemplo, si al momento de contraer nupcias se optó por llevar adelante una familia en la cual uno solo de los cónyuges era el proveedor económico y el otro cumplía sus funciones en el seno del hogar y en apoyo a la profesión del otro, no sería justo que al quiebre de esa elección se deje desamparado a aquél de los cónyuges que invirtió su tiempo en tareas que no se traducen en réditos económicos; en este caso, se le fijará una compensación económica que puede asumir distintas modalidades de pago: pensión, cuotas, etcétera. Nada impide que los cónyuges convengan su monto y forma de pago, pero, como se trata de un caso de protección legal con fundamento en la solidaridad familiar, ante la falta de acuerdo el juez puede determinar su procedencia y fijar su monto si correspondiere. Al tratarse de una herramienta destinada a lograr un equilibrio patrimonial, es necesario realizar un análisis comparativo de la situación patrimonial de cada uno de los cónyuges al inicio del matrimonio y al momento de producirse el divorcio, esto es, obtener una «fotografía» del estado patrimonial de cada uno de ellos, y, ante un eventual desequilibrio, proceder a su recomposición"27.

En esta línea de ideas, la compensación económica parece constituir un instituto eficaz para compensar la situación económica en que quedan los cónyuges con posterioridad al divorcio.

Debe quedar claro que este instrumento bajo ningún punto de vista puede ser utilizado para abrir el debate sobre la culpa de los cónyuges en el divorcio puesto que, al regularse el divorcio incausado, esa posibilidad ha quedado trunca. Vinculado con ello, Solari sostuvo que: "[l]a aplicación de la [compensación económica] debe tener el carácter de excepcional, pues no debe dejar de señalarse que en un régimen divorcista, el Estado debe garantizar que las partes tengan la posibilidad de formar o constituir una nueva familia. Tal situación, no debe limitarse a lo atinente a la libertad de poder contraer matrimonio, situación que resulta indiscutida con el renacimiento de la aptitud nupcial luego

${ }^{27}$ El resaltado nos pertenece. 
de la sentencia de divorcio, sino también desde el punto de vista económico o financiero, de modo tal que los efectos previstos para la ruptura matrimonial no desnaturalicen la disolubilidad del vínculo matrimonial. Para ello, el equilibrio de los efectos derivados del divorcio deben ser acordes con la idea del divorcio vincular, al disolverse el vínculo en vida de los cónyuges" ${ }^{\prime 28}$.

En sentido contrario al sostenido por Solari, consideramos que la aplicación de la compensación económica no debe ser excepcional sino que debe proceder en todos los casos en que se produzca un desequilibrio económico, de conformidad con lo establecido por el artículo 441 del CCyCN. El autor afirma que si con el divorcio renace la posibilidad de contraer un nuevo matrimonio, el/la excónyuge también debe contar con recursos económicos para iniciar dicho proyecto que se vería frustrado con la fijación de una compensación económica a favor de su expareja. Este argumento, por un lado, desvirtúa la finalidad protectoria del instituto que tiende a compensar una situación de empeoramiento económico de un cónyuge en beneficio del otro, que tiene su origen en el matrimonio y en la situación en que lo/la coloca el divorcio. Si esta postura se aplica a un caso donde la mujer se ha dedicado al cuidado de hijos/ as y a las tareas de hogar y el varón ha estado inserto en el mercado laboral (caso, por cierto, típico), la excepcionalidad a la que alude el autor implicaría desconocer el valor monetario del trabajo doméstico y de cuidados realizado por la mujer durante todo el matrimonio, que le ha impedido abocarse a una formación profesional o laboral. Asimismo, esa tesitura desconoce que el trabajo de la mujer en el cuidado de hijos/as y en las tareas domésticas es el que ha permitido el trabajo del cónyuge varón en el mercado laboral formal. Esta situación posiciona a la cónyuge en una peor situación económica en relación con el otro y ese empobrecimiento es precisamente el que se compensa.

Por otro lado, la postura del autor supone que el cónyuge que tiene a cargo el pago de una compensación económica no podrá afrontar un nuevo proyecto de pareja por falta de recursos económicos. Dicha suposición no tiene asidero dado que la fijación de la compensación, como se dijo, valora la disparidad económica de los excónyuges. Por lo tanto, si hay desigualdad económica significa que quien debe pagar la compensación se encuentra en una mejor situación económica que su excónyuge y, en consecuencia, tendrá los medios económicos para afrontarla, justamente gracias a que el trabajo doméstico y de cuidados de su excónyuge ha posibilitado esa situación.

En segundo lugar, el cese de la unión convivencial produce también ciertos efectos, entre ellos se regula la compensación económica.

28 SOLARI (2014). 
Así, el artículo 524 del CCyCN establece que, una vez finalizada la convivencia, el/la conviviente que sufre un desequilibrio manifiesto que signifique un empeoramiento de su situación económica con causa adecuada en la convivencia y su ruptura, tiene derecho a una compensación. Esta puede consistir en una prestación única o en una renta por un tiempo determinado que no puede ser mayor a la duración de la unión convivencial. Puede pagarse con dinero, con el usufructo de determinados bienes o de cualquier otro modo que acuerden las partes o en su defecto decida el/la juez/a.

Si los convivientes no pactan el derecho a la compensación económica a favor de uno/a, el artículo 525 del CCyCN establece que la pueden solicitar judicialmente ${ }^{29}$. Se debe determinar la procedencia y el monto de la compensación económica sobre la base de diversas circunstancias, a saber: a) el estado patrimonial de cada uno/a de los convivientes al inicio y a la finalización de la unión; b) la dedicación que cada conviviente brindó a la familia y a la crianza y educación de hijos/as, y la que debe prestar con posterioridad al cese; c) la edad y el estado de salud de los convivientes y de hijos y/o hijas; d) la capacitación laboral y la posibilidad de acceder a un empleo del o de la conviviente que solicita la compensación económica; e) la colaboración prestada a las actividades mercantiles, industriales o profesionales del otro conviviente; f) la atribución de la vivienda familiar.

La acción para reclamar la compensación económica caduca a los seis meses (al igual que en los casos de divorcio) contados desde que se produjo cualquiera de las causas de finalización de la convivencia enumeradas en el artículo 523 del $\mathrm{CCyCN}^{30}$.

Si comparamos la regulación de la compensación económica en los dos supuestos que expusimos, se observa que existen diferencias entre la compensación económica basada en el matrimonio y en la que tiene su fundamento en la unión convivencial.

Así, mientras que en la unión convivencial puede pedirse una compensación económica cualquiera haya sido la causal de cese de la convivencia, de

${ }^{29}$ En caso de supuesto de incumplimiento en el pago de la compensación económica, véase nota 26 del presente texto. Sea por divorcio o sea por cese de la unión convivencial, el procedimiento es el mismo (arts. 499 y ss., Código Procesal Civil y Comercial de la Nación y art. 719, CCyCN).

${ }^{30}$ Artículo 523. Causas del cese de la unión convivencial. La unión convivencial cesa: a) por la muerte de uno de los convivientes; b) por la sentencia firme de ausencia con presunción de fallecimiento de uno de los convivientes; c) por matrimonio o nueva unión convivencial de uno de sus miembros; d) por el matrimonio de los convivientes; e) por mutuo acuerdo; f) por voluntad unilateral de alguno de los convivientes notificada fehacientemente al otro; g) por el cese de la convivencia mantenida. La interrupción de la convivencia no implica su cese si obedece a motivos laborales u otros similares, siempre que permanezca la voluntad de vida en común (CCyCN, 2014). 
acuerdo con lo establecido por el artículo 524 del CCyCN (muerte, sentencia de ausencia con presunción de fallecimiento, matrimonio o unión convivencial con otra persona, mutuo acuerdo, voluntad unilateral notificada fehacientemente o cese de convivencia); en el matrimonio solo puede pedirse si la causal de la disolución del vínculo es el divorcio, teniendo en cuenta lo dispuesto por el artículo 441 del CCyCN (es decir, no procede por muerte ni por sentencia firme de ausencia con presunción de fallecimiento).

Por otra parte, en la unión convivencial, la posibilidad de pedir una compensación económica puede ser excluida mediante un pacto firmado entre los convivientes (artículos 514 y 515 del CCyCN). Los pactos entre convivientes pueden versar sobre cualquier cuestión siempre que respeten el piso mínimo obligatorio de derechos establecido por el CCyCN (asistencia, contribución a los gastos del hogar, responsabilidad por las deudas frente a terceros y protección de la vivienda familiar) y el orden público, el principio de igualdad y los derechos fundamentales de los convivientes. En cambio, en el matrimonio la compensación económica no puede ser excluida por pacto alguno, de conformidad con lo dispuesto por el artículo 446 del CCyCN que dispone que las convenciones matrimoniales solo pueden tratar sobre: a) la designación y avalúo de los bienes que cada uno/a lleva al matrimonio; b) la enunciación de las deudas; c) las donaciones que se hagan entre ellos; d) la opción que hagan por alguno de los dos regímenes patrimoniales (régimen de comunidad o régimen de separación de bienes). Además, el artículo 447 del $\mathrm{CCyCN}$ refuerza esta idea al regular que toda convención entre los futuros cónyuges sobre cualquier otro objeto relativo a su patrimonio es de ningún valor.

En cuanto a la modalidad de la compensación económica, mientras que en la unión convivencial solo puede ser una renta única o por tiempo determinado que no puede ser mayor al tiempo que duró la unión convivencial; en el matrimonio, la compensación económica puede consistir en una prestación única, en una renta por tiempo determinado o, excepcionalmente, por plazo indeterminado.

Tanto en la unión convivencial como en el matrimonio la acción para reclamar la compensación económica caduca a los seis meses contados, en el primer caso desde que se produjo cualquiera de las causas de finalización de la convivencia (artículo 525 del CCyCN) y, en el segundo caso -tal como se indicó con anterioridad-, desde que se dictó la sentencia de divorcio (artículo 442 del $\mathrm{CCyCN}$ ).

Como puede advertirse, esta normativa establece distinciones respecto de la compensación económica en el supuesto de divorcio y en el de cese de la unión convivencial. Esta regulación diferenciada no solo se establece en relación con la figura de la compensación económica sino que, en general, el matrimonio 
y las uniones convivenciales se norman de manera diferente. Así, el Código optó por regular las uniones convivenciales desde una postura intermedia y, a la vez, diferenciada del matrimonio. En los Fundamentos del Anteproyecto de CCyCN (2014), la Comisión redactora sostuvo: "En la tensión entre autonomía de la voluntad (la libertad de optar entre casarse y no casarse, cualquiera sea la orientación sexual de la pareja) y el orden público (el respeto por valores mínimos de solidaridad consustanciales a la vida familiar), el anteproyecto adopta una postura intermedia, al reconocer efectos jurídicos a la convivencia de pareja, pero de manera limitada. Mantiene diferencias entre dos formas de organización familiar: la matrimonial y la convivencial, distinciones que se fundan en aceptar que, en respeto del art. 16 de la Constitución Nacional, es posible brindar tratamiento diferenciado a modelos distintos de familia".

En tanto recepta la familia matrimonial y la familia convivencial, apartándose del modelo único familiar matrimonial, el Código se enmarca en un paradigma de igualdad y no discriminatorio, en consonancia con la realidad y la pluralidad familiar ${ }^{31}$. La igualdad es un principio constitucional (artículo 16, Constitución Nacional de la República Argentina - CN) y convencional (artículo $2^{\circ}$, incisos b y c y artículo16, CEDAW) ${ }^{32}$. Estos principios atraviesan la regulación del matrimonio y de la unión convivencial y su ruptura en el marco del proceso de constitucionalización del derecho privado. Éste alude a la tendencia en Argentina a la aplicación directa e inmediata de la Constitución Nacional y de los Tratados Internacionales de Derechos Humanos en el derecho de familia (art. 75, inc. 22 $\mathrm{CN}$ ). Como resultado se superan: "[l]os textos [que] hasta ahora regularon los derechos de los ciudadanos sobre la base de una igualdad abstracta, asumiendo la neutralidad. El Código [nuevo] busca la igualdad real y desarrolla una serie de normas orientadas a plasmar una verdadera ética de los vulnerables" ${ }^{\prime 33}$.

\footnotetext{
${ }^{31}$ De acuerdo a los datos que arroja el último Censo Nacional de Población, Hogares y Viviendas 2010, en la Argentina casi 4 de 10 personas que viven en pareja lo hacen en una convivencia no matrimonial (38\%). Disponible en: http://www.indec.gov.ar/nivel4_default.asp?id_tema_1=2\&id_tema_2=41\&id_ tema_3=135 [visitado el 20 de junio de 2017].

En relación con esas estadísticas, se ha sostenido: "Se trata de un número que aumenta conforme dos fenómenos socioculturales que la Reforma tampoco podía desoír a la hora de regular: i) la población más joven que cohabita antes de casarse, muchas veces a 'modo de prueba' y ii) la población de sectores sociales vulnerables en términos de derechos económicos, sociales y culturales que, en muchos casos, no tiene acceso a un registro civil o que, debido a esa situación de vulnerabilidad, poco es lo que pueden verdaderamente elegir en términos de autodeterminación del plan de vida, incluido el familiar" (De LA TORRE, 2014).

32 Cedaw: En castellano refiere a la Convención sobre la eliminación de todas las formas de discriminación contra la mujer.

33 HightON (2015), p. 5.
} 


\subsection{La aplicación de la compensación económica. Desafíos para la práctica legal}

El reconocimiento del derecho a la compensación económica se inscribe en el marco de los instrumentos de derecho internacional de los derechos humanos (como la CEDAW), de la Constitución Nacional argentina (cuya reforma del año 1994 otorgó jerarquía constitucional a dichos tratados vía el artículo 75 inc. 22), de la Convención Belem do Pará (que si bien fue ratificada por Argentina no goza de jerarquía constitucional, pero aun así se encuentra por encima de la normativa interna) y de la ley de Protección integral para prevenir, sancionar y erradicar la violencia contra las mujeres en los ámbitos en que desarrollen sus relaciones interpersonales ${ }^{34}$.

En este contexto, la compensación económica resulta una relevante incorporación del $\mathrm{CCyCN}$, puesto que implica una herramienta protectoria valiosa para compensar las situaciones de desigualdad que, en general, aun hoy dejan a las mujeres en un estado de desamparo al persistir un sistema de familia patriarcal que sostiene la división estereotipada de roles entre mujeres y varones ${ }^{35}$. Asimismo, en línea con esta regulación, el CCyCN reconoce expresamente el valor económico de las tareas domésticas y de cuidados al disponer que los cónyuges deben contribuir a su propio sostenimiento, el del hogar y el de hijos/ as comunes, en proporción a sus recursos -durante el matrimonio o la unión convivencial-y que el trabajo en el hogar es computable como contribución a las cargas (artículos 455 y 520).

A continuación nos detenemos en dos campos de problemas interconectados que alcanzan a las compensaciones que estamos analizando cuando no son abordadas adecuadamente. Por un lado, la violencia patrimonial que podría ejercerse hacia las mujeres de no atender a esta nueva figura (por ser la parte comúnmente afectada en este tipo de compensaciones en parejas heterosexuales). Por el otro, los alcances que podría tener lo que se conoce como el patrimonio invisible en la cuantificación de las compensaciones y, de no ser considerado, su articulación con modos de violencia patrimonial.

\footnotetext{
${ }^{34}$ Ley Nacional No 26.485, de 2009.

${ }^{35}$ En el presente texto se entiende por patriarcado o discursos patriarcales (la familia patriarcal, por ejemplo), a modos de jerarquización entre los seres humanos en donde un determinado tipo de cuerpovarón-adulto-heterosexual (lo que se dice acerca de ese cuerpo y lo que se hace o debe hacer con él) se vuelve relevante en tanto que relación de poder desigual sobre otros sujetos (por ejemplo, las mujeres). Así, en una cultura patriarcal, la configuración social hegemónica que da forma a la cultura legal se sostiene sobre este principio de jerarquía que produce desigualdad y exclusión, articulado con otros organizados a través de marcas de clase, etnia, raza, estatus migratorio, etcétera.
} 
En primer lugar en cuanto a la violencia patrimonial, la ya mencionada Ley Nacional de Protección integral para prevenir, sancionar y erradicar la violencia contra las mujeres en los ámbitos en que desarrollen sus relaciones interpersonales, define que la violencia económica y patrimonial es la que se dirige a ocasionar un menoscabo en los recursos económicos o patrimoniales de la mujer, a través de la limitación de los recursos económicos destinados a satisfacer sus necesidades o la privación de los medios indispensables para vivir una vida digna (artículo $5^{\circ}$, inc. $4^{\circ}$, punto c). De la norma se sigue que la falta de consideración de las compensaciones por trabajo doméstico y de cuidados, cuando se encuentran dados los supuestos fácticos para que ellas procedan, puede constituirse en un caso de violencia económica y patrimonial al vulnerar los derechos económicos de las mujeres, aún más en el contexto de la división sexual del trabajo y de la desigualdad estructural. Dicho en otros términos y para un caso en particular, sería causa de descapitalización o empobrecimiento de la cónyuge o la conviviente ${ }^{36}$. Este aspecto deberá ser especialmente tenido en cuenta por quienes están en el rol de ejercicio de la justicia en todos los órdenes, con la responsabilidad y consecuencias que ello acarrea.

En este sentido, advertimos que la posibilidad de renunciar a la compensación económica en el caso de las uniones convivenciales, podría dejar a muchas mujeres en una situación de desprotección y tener como efecto la violencia patrimonial. En tal caso, sostenemos que las mujeres deberían recibir un asesoramiento adecuado para que no pacten la renuncia a este derecho. $\mathrm{Y}$, de todas formas, si renunciaran creemos que procedería un planteo judicial que cuestione tal renuncia con fundamento en el artículo 515 del $\mathrm{CCyCN}$ que establece que los pactos de convivencia no pueden ser contrarios al orden público, ni al principio de igualdad de los convivientes, ni afectar los derechos fundamentales de cualquiera de los integrantes de la unión convivencial. En esta línea, la renuncia al derecho a pedir compensación económica realizada por una mujer que se encuentra en una posición de desigualdad respecto de su exconviviente vulneraría el principio de igualdad (de raigambre constitucional y convencional) y los derechos fundamentales de la mujer a la no discriminación consagrados en el artículo $2^{\circ}$, incisos b y c y el artículo 16 de la CEDAW.

\footnotetext{
36 PITCH (1998). En países como Italia las pensiones económicas tienen como criterio de procedencia la prueba de la situación de necesidad de quien las solicita (véase PІтсH, 1998). En cambio en Argentina, el criterio para su fijación es la situación de desequilibrio económico que ha producido un empobrecimiento de quien la solicita y que se debe compensar. En este sentido la normativa argentina tomó como fuente el artículo 97 del Código Civil español, de lo que se puede inferir que, bien aplicada, puede ser una herramienta superadora, por ejemplo, de la italiana. Con todo y desde el derecho comparado, habría que revisar qué impacto han tenido las compensaciones analizadas en España y qué aspectos habría que mejorar de esa experiencia en nuestro singular contexto.
} 
Refuerzan este argumento los artículos $1^{\circ}$ y $2^{\circ}$ del CCyCN que, en relación con la aplicación, disponen que los casos que rige el Código deben ser resueltos según las leyes que resulten aplicables, conforme con la Constitución Nacional y los tratados de derechos humanos. Respecto de la interpretación, se establece que la ley debe ser interpretada teniendo en cuenta las disposiciones que surgen de los tratados sobre derechos humanos, los principios y los valores jurídicos, de modo coherente con todo el ordenamiento ${ }^{37}$.

En segundo lugar, consideramos que otro desafío para la práctica legal será el de valorar el patrimonio invisible de la familia al momento de fijar la compensación económica ${ }^{38}$.

Siguiendo la postura de Pitch, entendemos que el patrimonio invisible en parejas heterosexuales está representado por: "[l]a carrera y el éxito en el trabajo del marido [...] que se deben en gran parte a la inversión de tiempo, energías y trabajo que la mujer le ha quitado a su propia (posible) carrera tanto para dispensar al marido de las obligaciones de cuidar a hijos o mayores, como para proporcionarle la ayuda material, afectiva y psicológica necesaria para dedicarse al trabajo y conseguir resultados satisfactorios ${ }^{\prime 39}$. De asumirse este criterio frente a las compensaciones que estamos tratando, no sólo deberá evaluarse el estado patrimonial de cada uno de los integrantes de la pareja en términos contables, es decir, los bienes y las cuentas bancarias que cada uno/a posea, sino también se deberá valorar el patrimonio invisible que ha permitido y permitirá en el futuro una mejor inserción en el mercado laboral de uno de los cónyuges, en desmedro de quien relegó su potencialidad para el desarrollo económico propio $^{40}$.

El CCyCN, cuando regula las circunstancias que deben tenerse en cuenta para fijar la compensación económica, enumera entre otras: el estado patrimonial de cada uno de los cónyuges al inicio y a la finalización de la vida matrimonial; la dedicación que cada cónyuge brindó a la familia y a la crianza y educación de los hijos durante la convivencia y la que debe prestar con posterioridad al divorcio; la edad y el estado de salud de los cónyuges y de los hijos; la capacitación laboral y la posibilidad de acceder a un empleo del cónyuge que solicita

\footnotetext{
37 En el marco del nuevo CCyCN argentino, además del análisis de las compensaciones económicas por trabajo doméstico y de cuidados no remunerado, habría que evaluar si existen otros factores que puedan incidir en la descapitalización o el empobrecimiento de las mujeres frente a la disolución del vínculo marital o convivencial.

38 El patrimonio invisible de la familia tiene vinculación directa con el criterio de coste de oportunidad analizado en este texto (véase apartado 2.2.).

39 РітCH (1998), p. 146.

40 Pellegrini (2014).
} 
la compensación económica (artículo 442, incisos a, b, c y d). Estas pautas establecidas por el $\mathrm{CCyCN}$, interpretadas de manera integral, permiten valorar el patrimonio invisible de las familias.

Luego, teniendo en cuenta que la normativa argentina actual cuenta con dos regímenes patrimoniales del matrimonio, el de comunidad y el de separación de bienes, vale mencionar que la compensación económica procede en ambos regímenes. Una vez más la mirada debe estar puesta en la finalidad del instituto que tiende a compensar el desequilibrio económico producido por la ruptura del vínculo. Por lo tanto, aun en el régimen de comunidad en el que, luego del divorcio, los patrimonios se dividen entre los cónyuges por mitades, también podría producirse el desequilibrio económico que habilita la procedencia de la compensación económica. Dicho en otros términos y sin perjuicio de la partición de bienes, "quien hubiera asumido las tareas hogareñas se encuentra en una situación de desventaja frente a aquel cónyuge que desempeñó tareas laborales o profesionales, pues la capacitación laboral implica un beneficio de tipo patrimonial independientemente del capital ganancial que se pudiera haber generado" ${ }^{\prime 1}$.

Asimismo, en cuanto a la problemática planteada y en particular para el caso de parejas heterosexuales, Pitch sostiene: "en el momento de la separación, este patrimonio invisible tiende a quedarse totalmente en manos del marido, aunque se haya conseguido gracias a los esfuerzos y el trabajo de ambos cónyuges. Tiende a quedarse con el marido porque las normas son ambiguas y sujetas a la interpretación de jueces que a menudo no son para nada propensos, por cultura y por valores, a considerar este aspecto del trabajo femenino ${ }^{\prime 42}$. En este sentido, coincidimos con la autora en que este patrimonio tiende a quedarse en manos del varón, marido o conviviente. Sin embargo, afortunadamente la ley argentina ya no es ambigua ni abstencionista, al contrario, clara y expresamente establece el valor de las tareas domésticas y de cuidado a la vez que reconoce el derecho a pedir la compensación económica. Como se advierte, la ley se constituye en una herramienta valiosa para garantizar los derechos de las mujeres.

De todas maneras, si al momento de su aplicación no se tuviera en cuenta el patrimonio invisible, ello implicaría -como efecto- un supuesto de violencia económica y patrimonial en los términos anteriormente indicados, en tanto constituye un menoscabo en los recursos económicos o patrimoniales de la mujer, a través de la limitación de los recursos económicos destinados

41 Pellegrini (2014), p. 447.

42 PiтCH (1998), p.146. 
a satisfacer sus necesidades o la privación de los medios indispensables para vivir una vida digna.

Por lo tanto, en acuerdo con Pitch (1998), el desafío estará en la interpretación y aplicación del instituto que realicen los jueces y las juezas. En consecuencia, también allí estará el mayor desafío para quienes ejercemos la abogacía, tanto en la praxis legal como en la enseñanza e investigación en el campo jurídico. La tarea entonces estará centrada en exigir una interpretación y aplicación de la compensación económica que resulte acorde a los derechos económicos y patrimoniales de las mujeres consagrados constitucionalmente.

\section{Consideraciones finales}

A lo largo del presente texto nos dedicamos a analizar la figura de la compensación económica posdivorcio o cese de unión convivencial, introducida como novedad legislativa en el Código Civil y Comercial de la Nación Argentina (2014). Particularmente pusimos el foco en las compensaciones generadas por trabajo doméstico y de cuidados gratuitos.

En el primer apartado, desarrollamos desde perspectivas económicas y jurídicas feministas, algunos puntos teóricos y prácticos a tener en cuenta a la hora de la valoración y cuantificación de las compensaciones económicas. Indicamos diferentes vías, destacando el criterio de la tercera persona como la modalidad que en la actualidad está siendo utilizada en la corriente principal de la literatura comparada española para el cálculo de las compensaciones. La alusión a esta fuente comparada radica también en el hecho de que ha sido ésta una referencia importante para su inclusión en el nuevo Código argentino. A su vez, advertimos acerca de algunas limitaciones que posee este criterio, tales como el propio sector laboral de referencia sobre el que se establecería la comparación para el cálculo. Y, además, la valoración no sólo monetaria de este tipo de trabajo realizado de manera gratuita por miles de mujeres, sino también su valor simbólico imprescindible para la vida humana, tanto en las comunidades domésticas como estatales.

En segundo lugar, presentamos un análisis dogmático de la figura de la compensación en el nuevo CCyCN de Argentina, tanto en caso de divorcio como de cese de la unión convivencial, atendiendo a cada uno de los aspectos contenidos en la normativa.

Finalmente, introducimos dos campos de problemas para la praxis legal relativos, por un lado, a la violencia patrimonial como efecto de la no consideración de las compensaciones dada la situación fáctica de disolución del vínculo en los términos expuestos. Y, por el otro, la consideración de lo que se conoce como patrimonio invisible como dimensión fundamental a tener en cuenta en el momento de la cuantificación de estas compensaciones. Y, de 
no hacerlo, los efectos patrimoniales y económicos traducidos en términos de violencia hacia la parte afectada, generalmente la mujer en el caso de las parejas heterosexuales, y en el caso de las parejas del mismo sexo, la parte que haya sufrido un menoscabo económico al momento de la disolución del vínculo.

A nuestro entender, la consideración del trabajo doméstico y de cuidados no remunerados traducidos en términos de compensaciones en las situaciones indicadas son medidas jurídicas no sólo protectorias sino además garantistas de los derechos económicos y patrimoniales en especial de las mujeres. En este sentido, para que ello sea efectivo, la praxis legal y la labor interpretativa judicial deberán atender y reconocer, entre otros, los aspectos esgrimidos a lo largo del presente texto.

\section{BIBLIOGRAFÍA CITADA}

ACKERMAN, Mario (2000): "La discriminación laboral de la mujer en las normas legales y convencionales y en la jurisprudencia en la Argentina", en BIRGIN, Ley, Mercado y discriminación: El género del trabajo (Buenos Aires, Biblos), pp. 25-46.

Alabart, Anna; Carrasco, Cristina; Domínguez, Marius y Mayordomo, Maribel (2004): Trabajo con mirada de mujer. Propuesta de una encuesta de población no androcéntrica (Madrid, Consejo Económico y Social /CES).

Borderías, Cristina; Carrasco, Cristina y Alemany, Carme (1994): Las mujeres y el trabajo. Rupturas conceptuales (Barcelona, Icaria).

CARRASCO, Cristina (1991): El trabajo doméstico. Un análisis económico (Madrid, Ministerio de Trabajo y Seguridad Social).

CARRASCO, Cristina (1999): Mujeres y economía. Nuevas perspectivas para viejos y nuevos problemas (Barcelona, Icaria), edición 2003.

Carrasco, Cristina (2001): Tiempos, trabajos y géneros (Barcelona, Publicaciones de la Universitat de Barcelona).

Corral Talcianı, Hernán (2007): "La compensación económica en el divorcio y la nulidad matrimonial", en Revista Chilena de Derecho (Vol. 34, № 1), pp. 23-40.

Disponible en: http://www.scielo.cl/scielo.php?script=sci_arttext\&pid $=$ S0718-34372007000100003 [visitado el 27/06/2016].

De LA TORRE, Natalia (2014): "Algunas consideraciones en torno a la regulación proyectada en las uniones convivenciales. El difícil equilibrio entre el princio de autonomía y la solidaridad familiar", (Buenos Aires, SAIJ). 
Disponible en: http://www.saij.gob.ar/natalia-torre-algunas-consideraciones-torno-regulacion-proyectada-uniones-convivenciales-dacf1404562014-07/123456789-0abc-defg6540-41fcanirtcod [visitado el 20 de junio de 2017].

De Villota, Paloma (2003): Economía y Género. Macroeconomía, Política fiscal y liberalización. Análisis de su impacto sobre las mujeres (Barcelona, Icaria).

DurÁN, María de los Ángeles (1997): "La investigación sobre el uso del tiempo en España: algunas reflexiones metodológicas", en Revista Internacional de Sociología (vol. 18), pp. 163-190.

Esquivel, Valeria (2009): Uso del tiempo en la ciudad de Buenos Aires (Buenos Aires, Instituto de Ciencias / Universidad Nacional de General Sarmiento).

Fineman, Martha (2004): “Dependencia y deuda social: más allá de los mitos fundacionales", en GHERARDI (compiladora), Justicia, género y trabajo (Buenos Aires, Libraria / Red Alas), pp. 41- 61.

Fraser, Nancy (1997): lustitia Interrupta. Reflexiones críticas desde la posición postsocialista (Bogotá: Siglo Hombre Universidad de los Andes).

Highton, Elena (2015): "Una etapa histórica: la mujer en el nuevo Código Civil y Comercial de la Nación", en La Ley (Año LXXIX, NN 143, tomo 2015-D), pp. 5-10.

LERUSSI, Romina (2014): La retórica de la domesticidad. Política feminista, derecho y empleo doméstico en la Argentina (La Plata, EDULP/UNLP).

Machado, José Daniel (2003): "Acceso al ámbito de protección del decreto 326/56 para trabajadores del servicio doméstico", en Revista de Derecho Laboral (vol. 2.), pp. 277-319.

Mccloskey, Donald (1993): "Algunas consecuencias de una economía 'conjetiva'", en Ferber y Nelson (editoras), Más allá del hombre económico (Madrid, Cátedra), edición 2003, pp. 105-140.

Murillo, Soledad (1996): El mito de la vida privada. De la entrega al tiempo propio (Madrid, Siglo XXI), edición 2006.

PAUTASSI, Laura (2000): "El impacto de las reformas estructurales y la nueva legislación laboral sobre la mujer en la Argentina", en BIRGIN (editora), Ley, Mercado y discriminación: El género del trabajo (Buenos Aires, Biblos), pp. 107-146.

Pellegrinl, María Victoria (2014): "Comentario a los artículos 441 a 442", en Kemelmajer de Carlucci, Herrera y Lloverás (directoras), Tratado de Derecho de Familia según el Código Civil y Comercial de 2014 (Buenos Aires, Rubinzal Culzoni Editores), tomo II, pp. 412-480. 
Pérez Orozco, Amaia (2005): Perspectivas feministas en torno a la economía: el caso de los cuidados (Madrid, Consejo Económico y Social), edición 2006.

Picchio de Mercato, Antonella (2001): "Un enfoque macroeconómico 'ampliado' de las condiciones de vida", en CARRASCO, Tiempos, trabajos y géneros (Barcelona, Publicaciones de la Universitat de Barcelona), pp. 15-37.

PIтcH, Tamar (1998): Un sexo para dos. La construcción jurídica de género, sexo y sexualidad (Madrid, Trotta), edición 2003.

SilbauGH, Katharine (1996): "Convirtiendo el trabajo en amor: el trabajo doméstico y el derecho", en Gherardi, Justicia, género y trabajo (Buenos Aires, Libraria / Red Alas), edición 2012, pp. 123-174.

Soları, Néstor E. (2014): "Criterios de fijación de la prestación compensatoria", en: Revista de Derecho de Familia y de las Personas (№ 27, mes junio), sin páginas (revista online sujeta a suscripción, referencia: AR/DOC/1556/2014) (visitada el 5/09/2016).

VANDELAC, Louise (1985): "La economía doméstica a la salsa mercantil... o las valoraciones monetarias del trabajo doméstico", en Borderías et al., Las mujeres y el trabajo. Rupturas conceptuales (Barcelona, Icaria), edición 1994, pp. 151-208.

\section{LEGISLACIÓN}

Constitución Nacional Argentina (CN) (1853; 1994). Disponible en: http://bibliotecadigital.csjn.gov.ar/Constitucion-de-la-Nacion-Argentina-Publicaciondel-Bicent.pdf [visitada el 20/07/2016].

Convenio № 189, sobre Trabajo decente para trabajadores/as domésticos/as. Organización Internacional delTrabajo/OIT (2011), Ginebra, Suiza. Disponible en: http://www.ilo.org/dyn/normlex/en/f?p=1000:12100:0::NO::P12100_ ILO_CODE:C189 [visitada el 20/07/2016].

Fundamentos del Anteproyecto de Código Civil y Comercial de la Nación Argentina (2014). Disponible en: http://www.nuevocodigocivil.com/textosoficiales-2/ [visitada el 20/07/2016].

Ley Nacional № 26.485, sobre Protección integral para prevenir, sancionar y erradicar la violencia contra las mujeres en los ámbitos en que desarrollen sus relaciones interpersonales (2009). Disponible en: http://servicios.infoleg. gob.ar/infolegInternet/anexos/150000-154999/152155/norma.htm

[visitada el 20/07/2016].

Ley Nacional № 26.844 sobre Régimen Especial de Contrato de Trabajo para el Personal de Casas Particulares. Boletín Oficial, Buenos Aires, Argentina, 
12/04/2013. Disponible en: https://www.boletinoficial.gob.ar/ [visitada el 20/07/2016].

Ley Nacional No 26.994 sobre Código Civil y Comercial de la Nación (2014). Disponible en: http://www.infoleg.gob.ar/infolegInternet/anexos/235000-239999/235975/norma.htm [visitada el 20/07/2016]. 